\title{
Conhecimento sobre questões éticas do uso de dentes humanos entre cirurgiões- dentistas
}

\author{
Knowledge about ethical issues in the use of human teeth among undergraduate dentistry students \\ and dentists
}

Conocimiento sobre cuestiones éticas en el uso de dientes humanos entre estudiantes de pregrado en odontología y dentistas

Recebido: 25/11/2021 | Revisado: 03/11/2021 | Aceito: 06/12/2021 | Publicado: 16/12/2021

Danielly Dantas de Fonseca

ORCID: https://orcid.org/0000-0002-7571-2411 Faculdade Santa Maria, Brasil

E-mail: danielly.una16@hotmail.com

Layana Oliveira de Abreu

ORCID: https://orcid.org/0000-0003-2652-3021

Faculdade Santa Maria, Brasil

E-mail: layana_oliveira3103@hotmail.com

Yasmim Soares Silva

ORCID: https://orcid.org/0000-0002-7732-6741 Faculdade Santa Maria, Brasil

E-mail: yasmimsoaa@gmail.com

Arthur Henrique Vieira

ORCID: https://orcid.org/0000-0003-2496-3461 Faculdade Santa Maria, Brasil

E-mail: artvieira0142@gmail.com

Camila Silva Cardoso

ORCID: https://orcid.org/0000-0001-8182-2855 Faculdade Santa Maria, Brasil

E-mail: cardosocamila@gmail.com

Iohana Moésia Braga

ORCID: https://orcid.org/0000-0001-7680-0862 Faculdade Santa Maria, Brasil

E-mail: moesiaiohana@gmail.com

Ana Karina Almeida Rolim

ORCID: https://orcid.org/0000-0001-6910-2898

Universidade Estadual da Paraíba, Brasil

E-mail: ana.karina.almeida123@gmail.com

Patrícia Pereira Maciel

ORCID: https://orcid.org/0000-0002-0017-2924 Faculdade Santa Maria, Brasil

E-mail: patriciamaciel.p@ hotmail.com

Marcos Alexandre Casimiro de Oliveira

ORCID: https://orcid.org/0000-0002-7308-6779 Faculdade Santa Maria, Brasil

E-mail: marcosalexandre@gmail.com

Clarissa Lopes Drumond

ORCID: https://orcid.org/0000-0001-8944-852X

Faculdade Santa Maria, Brasil

E-mail: cladrumond@ hotmail.com

\begin{abstract}
Resumo
O objetivo deste estudo foi avaliar o conhecimento de cirurgiões-dentistas (CD) sobre as questões éticas que envolvem os dentes humanos. Trata-se de um estudo transversal, realizado com CD da cidade de Cajazeiras, Paraíba, Brasil. Para coleta de dados, foi aplicado um questionário via Google Forms. Nele, apresentava-se questionamentos sobre ética, extração dentaria e banco de dentes humanos (BDH). Foram incluídos os cirurgiões-dentistas inscritos no Conselho Regional de Odontologia (CRO) que atuam no Alto Sertão Paraibano e a busca pelos profissionais foi realizada diretamente no $\mathrm{CRO}$, por e-mail e telefone. Foram excluídos aqueles que não preencheram completamente o formulário. Este estudo foi aprovado pelo Comitê de Ética em Pesquisa sob parecer $\mathrm{n}^{\circ}$ 5056616. A análise dos dados foi realizada utilizando-se análise descritiva dos resultados. Participaram $18 \mathrm{CD}$ que atuam no alto sertão paraibano, com idade entre 22 e 41 anos. Dentre esses, a maioria era do sexo feminino, haviam se formado na rede privada de ensino e consideravam o dente como um órgão. Mais da metade dos CD afirmaram que doariam dentes extraídos em
\end{abstract}


seus consultórios para o banco de dentes. Ainda, quase a totalidade destes, nunca doaram dentes extraídos em seus consultórios ao BDH. Os cirurgiões-dentistas deste estudo, em sua maioria, desconhecem a existência de BDH no estado, as prerrogativas legais envolvendo a temática e os procedimentos necessários para doação de dentes aos bancos.

Palavras-chave: Dentes; Odontólogo; Bioética.

\begin{abstract}
The aim of this study was to assess the knowledge of dentists (CD) about ethical issues involving human teeth. This is a cross-sectional study, carried out with a CD in the city of Cajazeiras, Paraíba, Brazil. For data collection, a questionnaire was applied via Google Forms. In it, questions about ethics, dental extraction and human tooth bank (BDH) were presented. Dentists registered with the Regional Council of Dentistry (CRO) who work in Alto Sertão Paraibano were included and the search for professionals was carried out directly at the CRO, by email and telephone. Those who did not completely fill out the form were excluded. This study was approved by the Research Ethics Committee under opinion No. 5056616. Data analysis was performed using descriptive analysis of the results. Eighteen CDs who work in the upper sertão of Paraíba participated, aged between 22 and 41 years old. Among these, most were female, had graduated from the private school system and considered the tooth as an organ. More than half of CDs said they would donate teeth extracted in their offices to the tooth bank. Still, almost all of them never donated teeth extracted in their offices to the BDH. Most dentists in this study are unaware of the existence of BDH in the state, the legal prerogatives involving the subject and the necessary procedures for donating teeth to banks.
\end{abstract}

Keywords: Teeth; Dentist; Bioethics.

\title{
Resumen
}

El objetivo de este estudio fue evaluar el conocimiento de los dentistas (EC) sobre cuestiones éticas relacionadas con los dientes humanos. Se trata de un estudio transversal, realizado con un CD en la ciudad de Cajazeiras, Paraíba, Brasil. Para la recolección de datos, se aplicó un cuestionario a través de Google Forms. En él se presentaron preguntas sobre ética, extracción dental y banco de dientes humanos (BDH). Se incluyeron odontólogos inscritos en el Consejo Regional de Odontología (CRO) que trabajan en Alto Sertão Paraibano y la búsqueda de profesionales se realizó directamente en el CRO, por correo electrónico y teléfono. Se excluyó a quienes no cumplimentaron completamente el formulario. Este estudio fue aprobado por el Comité de Ética en Investigación con el dictamen No. 5056616. El análisis de los datos se realizó mediante análisis descriptivo de los resultados. Participaron 18 CD que trabajan en el sertão alto de Paraíba, con edades comprendidas entre los 22 y los 41 años. Entre ellos, la mayoría eran mujeres, se habían graduado del sistema escolar privado y consideraban el diente como un órgano. Más de la mitad de los $\mathrm{CD}$ dijeron que donarían dientes extraídos en sus oficinas al banco de dientes. Aún así, casi todos ellos nunca donaron los dientes extraídos en sus oficinas al BDH. La mayoría de los dentistas de este estudio desconocen la existencia de $\mathrm{BDH}$ en el estado, las prerrogativas legales que involucran al sujeto y los trámites necesarios para la donación de dientes a los bancos.

Palabras clave: Dientes; Odontólogos; Bioetica.

\section{Introdução}

O dente humano é um órgão e deve ser tratado, valorizado e ter a sua origem conhecida (Brasil, 1997). Esse órgão carrega material biológico de seres humanos, de onde, potencialmente, pode-se adquirir a identidade genética do indivíduo, mediante a extração do DNA nele presente (Pardine et al., 2001).

A perda dentária é considerada um dos principais agravos à saúde bucal atrelada à sua alta prevalência. Ela pode levar a impactos estéticos, funcionais, psicológicos e sociais no indivíduo (Barbato et al., 2007). Essa perda reflete a quantidade de carga de doenças bucais ao longo da vida, além de aspectos culturais e a decisão de extrair o dente como alternativa de tratamento odontológico (Gilbert et al., 1996).

Estudos epidemiológicos revelam que as perdas dentárias se constituem uma marca da diferença social em diversas sociedades. Grupos populacionais situados na base da hierarquia socioeconômica apresentam grande quantidade de perdas dentárias em relação aos situados no topo (Barbato et al., 2003). 
Os dentes humanos extraídos são utilizados em estudos de anatomia e histologia dentais, em laboratório de pré-clínica de endodontia e dentística, e também usados na pesquisa científica. Ainda, podem ser utilizados para colagem de fragmentos dentários afim de reconstituir um dente destruído por cárie, por exemplo (Aniceto-Freitas et al., 2010; Freitas et al., 2010).

O Código de Ética Odontológico afirma que o componente dentário, sendo um órgão que constitui o corpo humano, está de acordo com a lei brasileira de transplantes. Esta lei torna proibida a comercialização de dentes e prevê, no Artigo 5, pena de 3 a 8 anos de prisão e multa (Miranda; Bueno, 2012).

O comércio de dentes humanos extraídos é um fato que ainda hoje ocorre no recinto universitário devido à incessante necessidade na análise da anatomia dentária, nas disciplinas pré-clínicas das instituições de educação e nas pesquisas científicas (Imparato et al., 1996; Pupp et al., 1997; Tonolli et al., 1997). Embora existam dentes pré-fabricados no mercado odontológico, confeccionados com diferentes tipos de materiais, o elevado custo e a textura, que não reproduz com veracidade os dentes humanos, tornam desvantajoso o seu uso nas disciplinas pré-clínicas e nas pesquisas (Imparato et al., 2003). Pesquisas científicas dependem do armazenamento de material biológico para que sejam realizados seus experimentos. Qualquer material coletado em ambulatórios público, particular ou em instituições de ensino pertence ao indivíduo. Para ser utilizado, é necessário a doação do material pelo indivíduo que autoriza e legaliza a partir de um documento. Em caso dos dentes humanos doados, podem ser armazenados e utilizados em diferentes tipos de reservatórios para fins da pesquisa, como biobanco, biorepositório e para fins pesquisas e educacionais como banco de dentes (Brasil, 2011).

Os biobancos, conforme a resolução número 441 do Conselho Nacional de Saúde, apresentam-se também como uma coleção organizada de material biológico de natureza humana e suas respectivas informações e características (Brasil, 2011). Coleta-se e armazena-se para utilização em pesquisa, de acordo com regulamento ou normas técnicas, éticas e operacionais pré-definidas. Esta é sob responsabilidade e gerenciamento da própria instituição, sem fins comerciais (Souza; Greenspan, 2013).

Os biorepositórios possuem características muito semelhantes aos biobancos. Embora similares em seus objetivos, diferem quanto à organização, e período de manutenção das amostras. Isto pode interferir nos aspectos éticos finais, uma vez que não necessita do consentimento direto do CONEP (Comissão Nacional de Ética em Pesquisa), mas apenas da aprovação de comitês internos de ética em pesquisa.

Um Banco de Dentes Humanos (BDH) é uma instituição sem fins lucrativos, que deve ser vinculada a uma faculdade, universidade ou outra instituição. Sua finalidade é suprir as necessidades acadêmicas com o fornecimento de dentes humanos para pesquisa ou atividades didáticas (Nassif et al., 2003).

A utilização de órgãos ou tecidos humanos sem origem comprovada é considerada crime, desde fevereiro de 1997, a partir da Lei no 9.434 (Nassif et al., 2003). A valorização do elemento dental é um fato, muitas vezes, pouco respeitado pela maioria dos cirurgiões-dentistas, estudantes e por alguns profissionais vinculados à pesquisa científica. Estes podem utilizar grandes quantidades de dentes humanos em suas pesquisas, desconsiderando os aspectos éticos e legais que se referem à origem destes órgãos por desconhecer ou por negligencia (Nassif et al., 2003; Ferreira et al., 2003). Os respectivos aspectos éticos e bioéticos que cercam este assunto devem estar inseridos no ensino da Odontologia (Pires \& Cerveira, 2003).

Sabendo que o cirurgião-dentista é o responsável pelas condutas éticas que envolvam o paciente, bem como os dentes humanos extraídos, elaborar um estudo que verifique o conhecimento de cirurgiões-dentistas sobre essa temática é importante. As informações poderão nortear o ensino superior sobre as questões éticas evolvendo os dentes, bem como a elaboração de estratégias voltadas para os cirurgiões-dentistas para a regularização das doações dentárias.

O objetivo do presente trabalho é verificar o conhecimento dos cirurgiões-dentistas sobre as questões éticas que envolvem dentes humanos extraídos. 


\section{Metodologia}

Foi desenvolvido um estudo transversal de caráter exploratório com os cirurgiões-dentistas do alto sertão paraibano, seguindo o delineamento da Figura 1.

Figura 1 - Delineamento do estudo transversal.

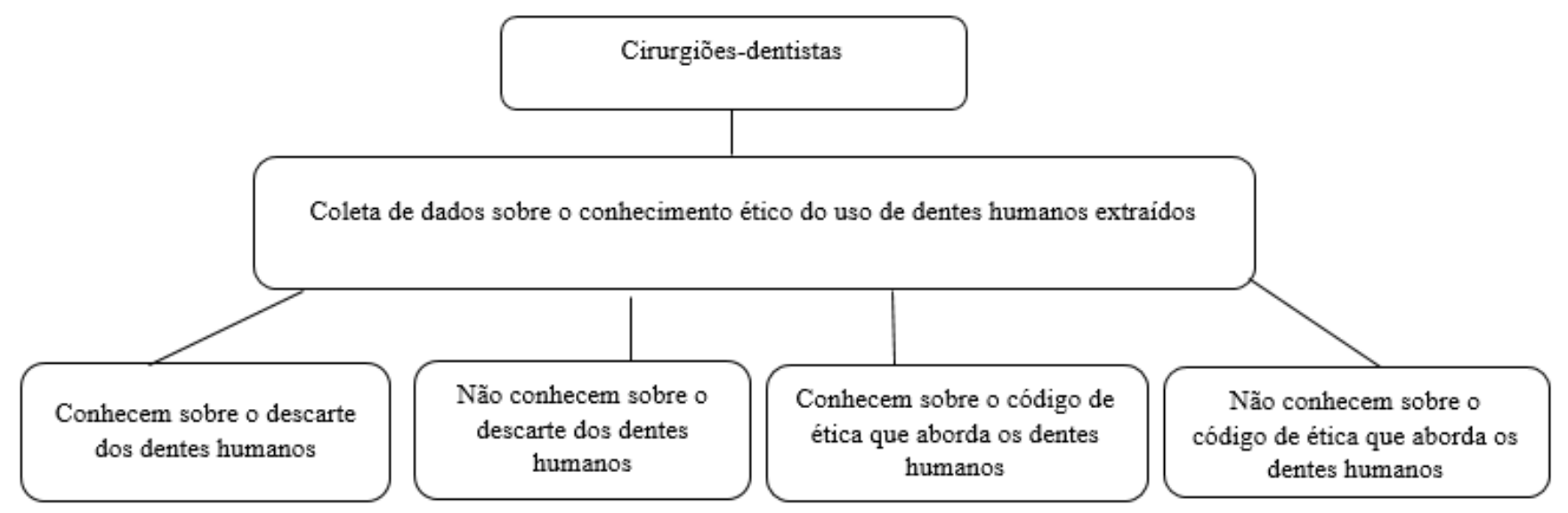

Fonte: Autores (2021).

Uma amostra por conveniência de 182 cirurgiões-dentistas do alto sertão da paraíba foi adotada. Para a presente investigação, foram incluídos os cirurgiões-dentistas inscritos no Conselho Regional de Odontologia (CRO) que atuam no Alto Sertão Paraibano. Aqueles profissionais que não preencheram completamente o questionário foram excluídos do estudo. Para contacta-los, o CRO passou as informações sobre e-mail e telefone. A pesquisa foi realizado no período de agosto a outubro de 2021.

Os cirurgiões-dentistas responderam a um questionário pré-estruturado com 17 perguntas através do aplicativo google forms. Este continha informações sobre o sexo, idade, instituição de formação, ano de conclusão do curso, curso de pósgraduação e qual área cursada; questionou-se acerca da matriz curricular da graduação se havia alguma unidade curricular que abordava a temática sobre dentes humanos; conhecimento do tópico a respeito dos dentes humanos no código de ética odontológico, protocolo de armazenamento do dente pós exodontia, conhecimento sobre termo de doação de dentes e termo de consentimento livre e esclarecido em caso de doação de dentes, conhecimento sobre banco de dentes, utilização de dentes humanos durante a graduação e procedência do dente.

Previamente ao estudo principal, foi realizado o teste e re-teste do questionário pré-estruturado. Além disso, foi realizado o treinamento da equipe de pesquisa, composta por dois pesquisadores. Este treinamento compreendeu a forma de abordagem para a convocação da pesquisa ao cirurgião-dentista.

Os dados obtidos a partir dos questionários foram inseridos, organizados e analisados no programa no Programa Statistical Package for Social Sciences (IBM SPSS Statistics for Windows, Version 22.0. Armonk, NY: IBM Corp). Este processo foi realizado por duas pessoas, sendo que uma digitou os dados e a outra conferiu. A análise estatística compreendeu a distribuição da frequência absoluta e relativa das variáveis do estudo.

Este estudo foi aprovado pelo Comitê de Ética em Pesquisa da Faculdade Santa Maria-PB sob o parecer ${ }^{\circ} 5056616$. Os cirurgiões-dentistas assinaram o Termo de Consentimento Livre e Esclarecido (TCLE) previamente no estudo. Foi garantido o direito de não identificação dos participantes. 


\section{Resultados e Discussão}

A taxa de resposta do presente estudo foi de $9,9 \%$ que correspondeu a 18 cirurgiões-dentistas que atuam no alto sertão paraibano, com idade entre 22 e 41 anos. Dentre esses cirurgiões-dentistas, 55,6\% (N=10) era do sexo feminino. Dos 18 cirurgiões-dentistas, 7 (sete) estão entre 22 a 24 anos. A maioria dos cirurgiões-dentistas deste estudo se formaram na rede privada de ensino $(72,2 \%)$ e os demais, $27,8 \%$, se formaram na rede pública de ensino. Aqueles que consideraram o dente como um órgão foi de $100 \%(\mathrm{n}=18)$ (Tabela 1$)$.

Os profissionais que doariam dentes extraídos em seus consultórios para o banco de dentes foi 83,3\% ( $\mathrm{n}=15)$ (Tabela 1). Aqueles que nunca doaram dentes extraídos em seus consultórios ao banco de dente foi 94,4\% (n=17) (Tabela1).

Quadro 1. Caracterização da amostra com dados da pesquisa sobre o conhecimento dos cirurgiões-dentistas sobre as questões éticas do uso de dentes humanos.

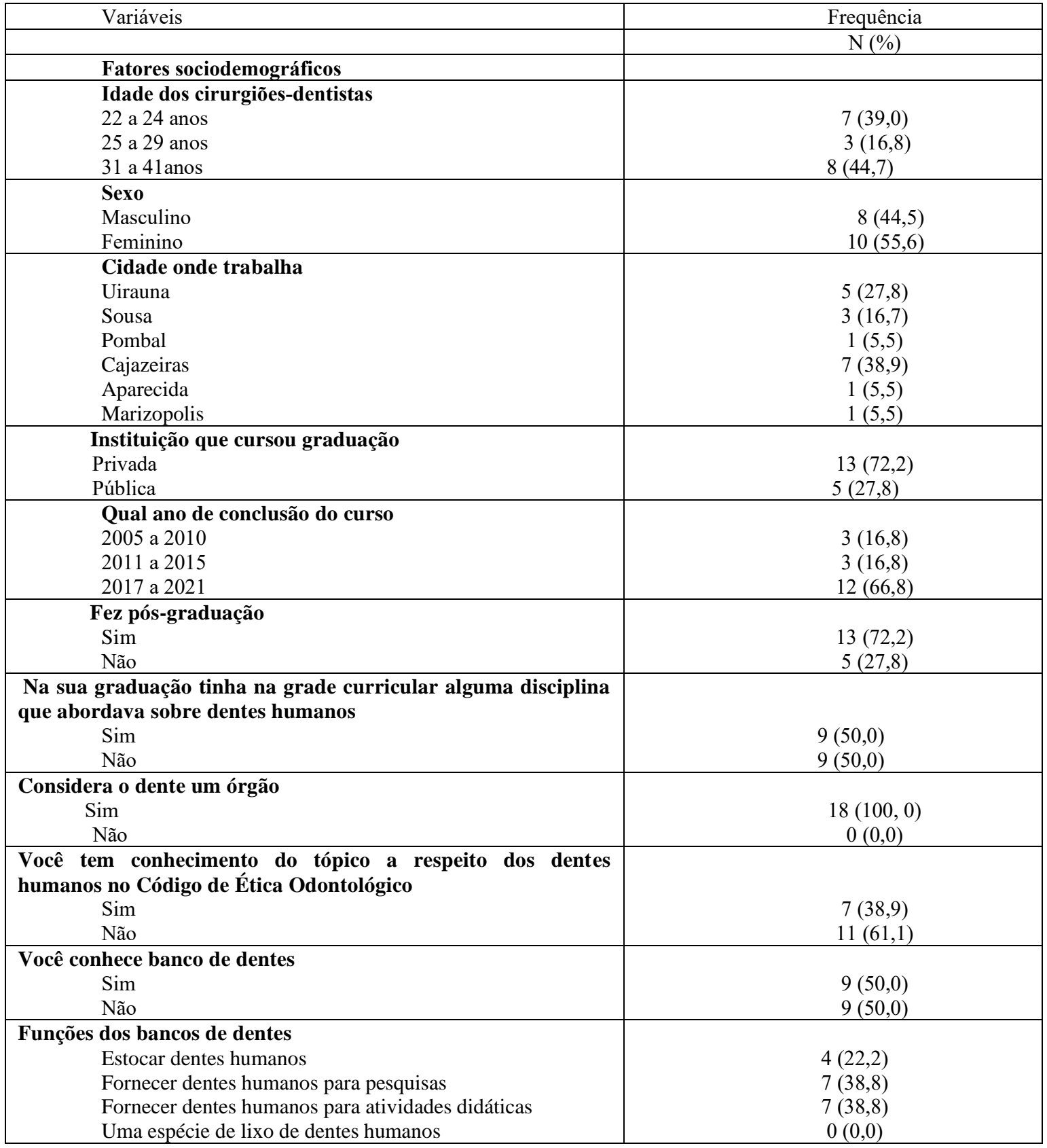




\begin{tabular}{|c|c|}
\hline $\begin{array}{l}\text { Doaria dentes extraídos em seus consultórios para o banco de } \\
\text { dentes }\end{array}$ & \\
Sim & $15(83,3)$ \\
Não & $0(0,0)$ \\
Talvez & $3(16,7)$ \\
\hline $\begin{array}{l}\text { Você já doou dentes extraídos no seu consultório para o banco } \\
\text { de dentes }\end{array}$ & $1(5,6)$ \\
Sim & $17(94,4)$ \\
Não & \\
\hline $\begin{array}{l}\text { Você sabe que a comercialização de dentes humanos está sujeita } \\
\text { a pena de reclusão de 3 a 8 anos de prisão }\end{array}$ & $6(33,3)$ \\
Sim & $12(66,7)$ \\
Não & $18(100,0)$ \\
\hline $\begin{array}{c}\text { Durante a graduação utilizou dentes humanos para práticas } \\
\text { laboratoriais }\end{array}$ & $0(0,0)$ \\
Sim & $9(50,0)$ \\
Não & $9(50,0)$ \\
\hline Sim Nim, sabe a procedência do dente & \\
Não & $10(55,6)$ \\
\hline $\begin{array}{l}\text { Participaria de alguma campanha para estimular a doação de } \\
\text { dentes extraídos para um banco de dentes humanos }\end{array}$ & $8(44,4)$ \\
Sim &
\end{tabular}

Fonte: Fonseca et al. (2021).

No presente estudo, todos os cirurgiões-dentistas consideram dentes humanos como órgão. Esse resultado corrobora com achados literário atuais, sendo um conceito consensual entre os dentistas brasileiros (Nassif et al., 2003; Gomes et al., 2013). No Brasil, os dentes humanos foram reconhecidos como órgão por meio de normatização do Conselho Nacional de Saúde, de $n^{\circ}$ 441/11, que trata do Banco de Dentes Humanos (BDH). A lei nacional de transplantes visa regulamentar a captação, a armazenar e a usar esse órgão, tanto nas pesquisas, quanto nos processos de formação, capacitação e aperfeiçoamento na área odontológica. Além disso, prever multa e reclusão àqueles que descumprirem os preceitos éticos elencados, a exemplo, a lei veda a comercialização e estimula a doação desse órgão de forma voluntária (Brasil, 2011; Poletto et al., 2010; Pereira, 2012).

A criação dos BDH teve início por volta dos anos 2000, e o seu objetivo engloba vedar a comercialização de órgãos, garantir a biossegurança e suprir as necessidades acadêmicas. Dessa forma, os BDH estarem obrigatoriamente vinculados a uma instituição de ensino. Têm, prioritariamente, a função de suprir a necessidade da demanda do órgão nas atividades de formação, ensino e pesquisa, o que cabe também o registro, higienização, esterilização, guarda e distribuição. Além disso, a atuação em campanhas e estratégias de captação, por meio de ações que envolvam a participação social (Silva et al., 2018).

Contudo, nesse estudo, mais da metade dos CD desconheciam o serviço de BDH, ainda que esse esteja presente em capítulo exclusivo do Código de Ética Odontológico. O estudo realizado por Pacheco-Silva (2018) e colaboradores apontou um resultado semelhante a este trabalho. Foi incluindo neste estudo, participantes que formaram a partir de 2005, sendo que o código apresenta o BDH desde tal ano, podendo se justificar tal achado a um déficit na implementação do assunto na matriz curricular das faculdades que estes cirurgiões-dentistas se formaram (Camargo; Batista; Unfer, 2019; Barbosa \& Silva, 2019).

Ressalta-se a resposta positiva de todos os participantes do estudo sobre a utilização de dentes humanos no processo de formação, contudo, $50 \%$ desses desconheciam a origem dos dentes utilizados. Esse achado resulta em uma cadeia de problemas, tanto biológicos, quanto sociais e civis, visto que, uma das funções dos BDH, é garantir a segurança biológica dos dentes utilizados. O BDH ainda visa atenuar, mitigar e até mesmo eliminar riscos à saúde dos graduandos. Neste contexto, a necessidade de reconhecimento da origem do órgão visa cumprir os preceitos éticos da profissão e do BDH, nessa prática, a 
autonomia dos sujeitos e/ou dos seus responsáveis foi violada e o crime de contrabando consumado, o que implica na possibilidade da aplicação das penalidades previstas (Brasil, 2011; Poletto et al., 2010; Pereira, 2012).

Mais adiante, ao serem questionados sobre as penalidades civis incumbidas ao comércio de dentes Humanos, parte significativa (66,7\%) dos entrevistados não sabia sobre a pena de reclusão, que se encontra no código de ética. Este documento enfatiza aos profissionais e estudantes da Odontologia o reconhecimento do elemento dental como um órgão. Essa informação muitas vezes é negligenciada ou desconsiderada por muitos profissionais, que por vezes compactuam e/ou estimulam a aquisição dos dentes a qualquer modo, embora o Código de Ética Odontológico explicita a pena de reclusão de 3 a 8 anos de prisão mais multa. (Pardini et al., 2001)

Conforme apresentado no estudo, uma parcela significativa dos CD demonstrava conhecimento superficial ou vazio sobre o Código de Ética Odontológico, não conseguindo compreender reflexões profundas. Dessa forma, reflete a necessidade de ampliação dos valores éticos profissionais, não só durante o processo de formação, mas também na prática assistencial diária. Aponta-se que o processo de educação continuada é também uma ferramenta importante para a garantia da qualidade do serviço e do cuidado prestado, incluindo-se nessa, a relevância do processo de formação continuada aos tutores (professores) e CD (Jacobucci \& Megid-Neto, 2011).

Nesse contexto, destaca-se a necessidade da realização de estudos ampliados acerca do tema. Apesar dos resultados desse estudo apontar uma deficiência dos CD sobre o tópico Código de Ética Odontológico e BDH, esses não podem ser extrapolados ao público geral, por se tratar de uma amostra por conveniência, sendo essa uma limitação encontrada pelos pesquisadores. Além disso, como os cirurgiões-dentistas responderam o questionário sobre experiência previas, o viés de memória pode estar presente. Considerando os resultados aqui apresentados que são relevantes a comunidade científica, há o estímulo para a elaboração de um estudo futuro com amostras representativas que visem avaliar o conhecimento dos CD e acadêmicos de odontologia sobre BDH e que permita análises estatísticas mais robustas. Além disso, outros estudos com desenhos mais elaborados que possam abordar estratégias de educação continuada sobre os aspectos éticos envolvendo dentes humanos e os cirurgiões-dentistas, como ensaios clínicos randomizados, são necessários.

\section{Conclusão}

Os resultados da presente investigação mostraram que a metade dos CDs entrevistados relataram não terem cursados unidades curriculares e/ou orientação sobre BDH durante o seu processo de formação, e mais da metade afirmou desconhecer as prerrogativas legais acerca desta temática. Esses achados sugerem a deficiência enfrentada pelos profissionais em contribuir com a captação de dentes humanos e consequentemente com o desenvolvimento da ciência, pesquisa e da prática. Além disso, sugerem a necessidade das instituições de ensino superior do curso de Odontologia abordarem em sua matriz curricular sobre essa temática.

Em contrapartida, ressalta-se a necessidade do apoio no processo de formação continuada dos profissionais de odontologia, a fim de aperfeiçoar a prática profissional em benefício das famílias e da coletividade.

\section{Referências}

Barbato, P. R., Nagano, H. C. M., Zanchet, F. N., Boing, A. F., \& Peres, M. A. (2007). Perdas dentárias e fatores sociais, demográficos e de serviços associados em adultos brasileiros: uma análise dos dados do Estudo Epidemiológico Nacional (Projeto SB Brasil 2002-2003). Cadernos de Saúde Pública, 23, 1803-1814.

Barbosa, J. R. A., \& Silva, S. A. R. (2019). Políticas de formação de professores para a educação profissional: trajetórias e desafios. Brazilian Journal of Development, 5(10), 17580-17593.

Batista, A. K., de Camargo, F. D., \& Unfer, B. (2019). Ética e moral: reflexões de dentistas do serviço público. Revista Bioética, 27(2).

Brasil (1997). Lei $n^{\circ} 9.434$ de 4 de fevereiro de 1997. https://www.planalto.gov.br/ccivil_03/LEIS/L9434.htm. 
Brasil (2011). Resolução $n^{\circ} 441$, de 12 de maio de 2011, diretrizes para análise ética de projetos de pesquisas que envolvam armazenamento de material biológico humano ou uso de material armazenado em pesquisas anteriores. Diário Oficial União, Seção 1. https://conselho.saude.gov.br/resolucoes/2011/Reso441.pdf

Ferreira, E. L., Fariniuk, L. F., Cavali, A. É. C., Baratto Filho, F., \& Ambrósio, A. R. (2003). Banco de dentes: ética e legalidade no ensino, pesquisa e tratamento odontológico. Rev. bras. odontol, 120-122.

Freitas, A. B. D. A. D., Castro, C. D. L. D., Sett, G. D. S. J., Barros, L. M. D., Moreira, A. N., \& Magalhães, C. S. D. (2010). Uso de dentes extraídos nas pesquisas odontológicas publicadas em periódicos brasileiros de acesso online gratuito: um estudo sob o prisma da bioética. Arquivos em Odontologia, 46(3), $136-143$.

Gilbert, G. H., Paul Duncan, R., \& Shelton, B. J. (2003). Social determinants of tooth loss. Health services research, 38(6p2), $1843-1862$.

Gomes, G. M., Gomes, G. M., Pupo, Y. M., Gomes, O. M. M., Schmidt, L. M., \& Kozlowski Junior, V. A. (2013). Utilização de dentes humanos: aspectos éticos e legais. Revista Gaúcha de Odontologia, 61, 477-483.

Jacobucci, D. F. C., \& Megid Neto, J. P. (2011). Passado e presente da formação continuada de professores nos Centros e museus de ciências brasileiros. In VIII Encontro Nacional de Pesquisa em Educação em Ciências; I Congreso Internacional de Investigación en Enseñanza de las Ciencias.

Imparato, J. C. P. (2003). Banco de Dentes Humanos. Curitiba: Editora Maio, cap. 2, p. 35-6.

Imparato, J. C. P. (1996). Dente pode ser reciclado. Interativo-ABC, 6.

Miranda, G. E., \& Bueno, F. C. (2012). Banco de dentes humanos: uma análise bioética. Revista Bioética, 20(2), $255-266$.

Nassif, A. C. D. S., Tieri, F., Ana, P. A. D., Botta, S. B., \& Imparato, J. C. P. (2003). Estruturação de um banco de dentes humanos. Pesquisa Odontológica Brasileira, 17, 70-74.

Pardini, V. C., Ferreira, A. C. S., Gomes, K. B., \& Rodríguez, S. L. B. (2001). Uso do DNA proveniente de polpa dentária para identificação humana: relato de caso e técnica. Rev Cons Reg Odontol Minas Gerais, 7(1), 33-5.

Pires, L. A. G., \& Cerveira, J. (2003). A bioética na Odontologia. Stomatos, 9(17), 7-12.

Pereira, D. Q. (2012). Banco de dentes humanos no Brasil: revisão de literatura. Revista da ABENO, 12(2), $178-184$.

Poletto, M. M., Moreira, M., Dias, M. M., Lopes, M. D. G. K., Lavoranti, O. J., \& Pizzatto, E. (2010). Banco de dentes humanos: perfil sócio-cultural de um grupo de doadores. Revista Gaúcha de Odontologia (Online), 58(1), 91-94.

Pardini V. C., Ferreira A. C. S., Gomes K. B., Rodrigues S. L. B. Uso do DNA proveniente da polpa dentária para identificação humana. Rev CROMG. 7:33-5.

Puppo, J. A. C. (1997). “Organização do Banco de Dentes de decíduos da faculdade de Odontologia” - In: JORNADA ACADÊMICA DE ARARAQUARA "PROF. Dr. CARLOS ALBERTO DE SOUZA COSTA" Araraquara, 1997. Anais. Araraquara: UNESP, (Resumo n.8).

Tonolli, G., Espejo, X. C. Z., Camargo, M. C. F., Franco, A. E. A., \& Imparato, J. C. P. (1997). Colagem de fragmentos dentários em molares decíduos. Jornada Odontológica de Araras "Prof. Nelson de Queiroz Mistura” e Jornada da Associação Paulista de Cirurgiões Dentistas de Araras, 50.

Silva, T. P. D., Sousa, J. P. D., Rabello, P. M., \& Santiago, B. M. (2018). Avaliação do conhecimento de graduandos de odontologia de uma instituição de ensino superior quanto à ética profissional. Rev. Bras. Odontol. Leg., 28-38.

Souza, Y. G., \& Greenspan, J. S. (2013). Biobanking past, present and future: responsibilities and benefits. AIDS (London, England), 27(3), 303.

Vasconcelos, U. S., Silva Neto, A. P., Martins, G. A. S., Sipaúba, G. M. O., Moura, W. L., \& de Moura, C. D. V. S. (2018). Conhecimento dos cirurgiõesdentistas sobre Banco de Dentes Humanos. Revista da ABENO, 18(2), 20-26. 